\title{
Energy ethics
}

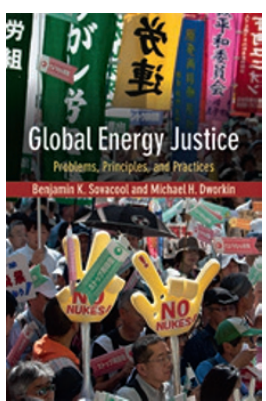

\author{
Global Energy \\ Justice: Problems, \\ Principles, and \\ Practices
}

by

Benjamin K. Sovacool and MichaelH.Dworkin

CAMBRIDGE

UNIVERSITY PRESS:

2014. PP391. $€ 22.99$

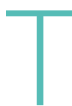

here is a great deal of contention in public, political, and academic discussions about the technical and scientific issues related to energy use and climate change. Such issues include the feasibility of replacing fossil fuels with alternative energy sources, and the rapidity with which average global temperatures have changed in the past and are likely to change in the future. There is considerable disagreement and uncertainty about some of the factual claims made in these discussions. But much of the acrimony, while often apparently centred on the science, probably stems from often-unacknowledged differences in ethical perspectives among scientists, policymakers, and laypeople.

In Global Energy Justice,

Benjamin Sovacool and Michael Dworkin highlight the importance of the ethical issues surrounding decisions about energy sources and systems, as well as the environmental consequences of these decisions. They develop and explicate 'energy justice' as a concept and a tool to help clarify what is at stake with decisions about energy use and who benefits from and are harmed by - the decisions that are made. Their overall goal is to show how justice theory can help us make decisions about energy.

What constitutes justice is, of course, not a simple matter. To help guide them in their thinking on the topic, Sovacool and Dworkin draw on the ideas of philosophers both ancient and modern - including Plato, Aristotle, Kant, Amartya Sen, John Rawls, and Dale Jamieson — and arrive at a fairly sensible way of thinking about justice. They consider two primary dimensions of justice, distributive and procedural. Distributive justice entails equitably sharing the benefits and burdens of energy production and consumption across individuals and societies.
Procedural justice is concerned with fairly including people and communities in decision-making about energy systems.

The heart of the book involves examining eight different energy problems/topics, each of which is used to illustrate a distinct justice theme considered in a global context. There is a chapter dedicated to each topic, organized around three 'eternal questions': What is reality? What is justice? And what is to be done? The authors consider a number of justice principle/energy problem couples: virtue/energy efficiency, utility/energy externalities, energy/human rights, energy decisions/due process, energy poverty/ welfare, energy subsidies/freedom, energy resources/future generations, and fairness and responsibility/climate change. These combinations are appropriate, even if not representing essential and singular pairings, as each justice theme has implications for many energy problems and each problem is connected with many facets of justice. The presentations of the reality of each problem are quite good, explaining the social and technical aspects of the topic in a clear and thorough manner. The discussions of justice nicely convey the complexity and subtlety as well as the immense importance - of reflecting on ethics, fairness, and freedom, among other concepts. Although not especially original, the suggestions as to what is to be done are perfectly reasonable if not detailed in offering guidance about how to overcome the political and economic obstacles to changing the status quo.

Climate change is discussed at various points throughout the book, and the authors explain how it is entwined with many other energy issues. Their summary of the widespread, yet unequally experienced, consequences of climate change clearly makes the case that the coming years may present great difficulties to societies if there is not a sharp change from business-asusual practices. They highlight how the threat of climate change raises questions about how to justly consider future generations, a theme they develop more in the chapter on energy resources. They emphasize that the striking inequality in accountability for contributing to climate change, where the wealthiest nations bear most of the responsibility for generating greenhouse-gas emissions, is central to considerations of justice.

The just solution they offer to the climate crisis is one advocated by many activists: affluent nations need to dramatically reduce their greenhouse-gas emissions, and all nations need to converge on a level of emissions that is sufficient to allow for acceptable living standards. The authors suggest the use of a greenhouse development rights (GDR) framework, where the nations most responsible for past emissions take on a disproportionately large share of the costs associated with addressing climate change and provide resources to help less-affluent nations 'develop. They suggest that the funds from GDR be used to help those communities most in need to implement climate change adaptation projects. They also advocate the development of 'stabilization wedges', which change specified activities over time to reduce greenhouse-gas emissions. All of these are good ideas, but Sovacool and Dworkin do not offer any new insights into how they might be successfully implemented in the global political context where many of the most powerful nations, corporations, and individuals profit from the current state of affairs.

This book prompts readers to think about a broad range of issues. It raises challenges that scientists and activists concerned about climate change would do well to consider. It also pushes us to think not simply about climate justice, but more broadly about energy justice. The most important change to prevent dramatic shifts in the global climate is reducing/eliminating the use of fossil fuels.

But there are costs associated with other energy sources that raise a variety of justice issues. Thinking of implications for justice of our energy decisions more broadly may help, for example, to curb the enthusiasm some have for nuclear power. Broadening our focus to include the justice consequences of all types of energy sources does exacerbate the difficulties entailed in addressing climate change. However, it could also force us to devise more radical solutions to our energy problems, as well as environmental problems more generally, that may help ensure the well-being of humans and the countless other species on this planet into the future.

\section{REVIEWED BY RICHARD YORK}

Richard York is in the Department of Sociology and Environmental Studies, University of Oregon, Eugene, Oregon 97403-1291, USA. e-mail:rfyork@uoregon.edu 